DOI 10.37882/2500-3682.2021.02.21

\title{
ТЕОРЕТИЧЕСКОЕ ОСМЫСЛЕНИЕ ФЕНОМЕНА «ПРАВОВОЕ ПОВЕДЕНИЕ» В ПСИХОЛОГИИ ЛИЧНОСТИ
}

\section{THEORETICAL CONCEPTUALIZATION OF THE PHENOMENON «LEGAL BEHAVIOR» IN PSYCHOLOGY OF PERSONALITY}

\section{Z. Myasnikova}

Summary: The article is dedicated to the research of legal behavior in the sphere of psychology of personality. This concept traditionally has an attitude to juridical scientific and practical field and is studied through two opposite aspects - lawful and illegal.

The actuality and requirement in conceptualization of this scientific direction is explained by the fact, that all the researches due to legal behavior are discussed only within the law field. But as for the author of the article, this category also has to be studied in the psychological field. The aim of the article lies in an attempt of analysis of the term «legal behavior» through the sphere of psychology of personality.

The influence factors were defined there by the method of system analysis of scientific sources. Among them the author's distinguished life conditions, education and morality levels, social environment, individual life experience, life situation.

In the conclusion the author noted, that in every concrete life situation due to person's legal behavior some factors will be more pronounced but some of them may not exert their influence at all.

Keywords: legal behavior, lawful, illegal, asocial, influence factors, social environment, course of life, motive, requirement, morality level.
Мясникова Зоя Вячеславовна

Аспирант, Тихоокеанский государственный университет myasnikovazoya@yandex.ru

Аннотация: Статья посвящена исследованию правового поведения в рамках психологии личности. Данное понятие традиционно имеет отношение к юридическому научному и практическому полю и рассматривается в двух противоположных аспектах - правомерном и противоправном.

Актуальность и потребность осмысления данного научного направления объясняется тем, что все исследования относительно правового поведения рассматриваются исключительно в рамках правового поля, но, по мнению автора, данное понятие должно изучаться и в психологическом поле.

Цель статьи заключается в попытке анализа понятия «правовое поведение» через сферу психологии личности.

Методом системного анализа научных источников были определены факторы влияния на правое поведение, среди которых автор выделил условия жизни, уровень воспитания и нравственности, социальную среду, индивидуальный жизненный опыт, жизненную ситуацию.

В качестве выводов автор отметил, что в каждой конкретной жизненной ситуации применительно к правовому поведению личности некоторые факторы будут более ярко выражены, а некоторые могут не проявлять своего воздействия.

Ключевые слова: правовое поведение, правомерный, противоправный, асоциальный, факторь влияния, социальное окружение, жизненный путь, мотив, потребность, уровень нравственности.
K атегорию «правовое поведение» традиционно принято относить к понятиям юридического правового поля, а также психологического поля в аспекте юридической психологии. Термин «правовое поведение» едва ли можно назвать новым, при этом невозможно отрицать, что исследование вопросов, касающихся правового поведения, ведется исключительно в контексте правомерного или противоправного поведения, характеризуемого криминальной природой. Что же касается общих вопросов, специфики использования и сферы применения феномена «правовое поведение», отмечается потребность обстоятельного исследования данной категории.

Так, исследовательский интерес представляет сфера применения понятия «правовое поведение» для психологии личности. Актуальность и потребность осмысления данного научного направления объясняется тем, что все исследования относительно правового поведения рассматриваются в рамках правового поля, с акцентом: нарушил норму закона - противоправное поведение, соблюдаешь нормы - правомерное. На наш взгляд, подобная классификация слишком примитивная, в особенности, если мы затрагиваем глубокую научную сферу психологию личности.

В рамках настоящей научной статьи будет предпринята попытка теоретического анализа феномена «правовое поведение» в рамках психологии личности.

Факторы влияния на правовое поведение личности исследуются уже на протяжении долгого времени, наиболее выдающимися работами в данном направлении считаются работы психиатра и психолога В.М. Бехтерева. Он был убежден, что причина, по которой конкретный человек совершает противоправное действие, определяется не только его личностной составляющей, но и совокупностью всех условий его существования и взаимодействия с окружающей действительностью [3]. Автор подчеркивал, что каждый отдельный случай следует изучать детально, с акцентированием внимания на условия совершения противоправных действий, обстановку, 
в которой они происходили, а затем и на личностные особенности лица, совершающего такие действия.

Личность совершает поступки под воздействием приобретенного ею индивидуального опыта и действия каких-либо внешних факторов. Личность находится в социальной среде, в связи с чем неправильно было бы рассматривать ее обособленно от окружения, поскольку влияние окружения на человека может оказаться негативным. Также следует брать во внимание особенности нравственного воспитания личности, что для нее норма, а что безнравственно. Основы нравственности закладываются с раннего детства, что еще раз доказывает влияние определенных факторов на противоправное поведение личности.

Таким образом, представляется возможным выделение основных факторов, влияющих на правовое поведение личности, внешних и внутренних. К внешним относятся индивидуальный жизненный опыт, социальное окружение, удовлетворенность/неудовлетворенность жизненными условиями и потребностями. К внутренним - особенности воспитания, уровень нравственности.

Опираясь на факторы влияния правового поведения, считаем возможным сформулировать определение данного термина, под которым мы понимаем поведение личности с соблюдением нравственных и законодательных норм, принятых обществом и государством, которое не нарушает права и интересы других членов общества, не является социально опасным и не предполагает негативные последствия для окружающих. Противоправное же поведение, напротив, несет в себе асоциальную направленность и свидетельствует об образовавшемся конфликте между личностными и общественными интересами.

Правовое поведение человека в любом случае, противоправное оно либо правомерное, представляет собой активность индивида, другими словами, его действия, которые, в свою очередь, определяются структурой личности. Структура личности представляет собой сложную организацию, в которой сосредоточены биологическая природа человека, темперамент, нравственные начала и основы социальных отношений [6]. Главным признаком того, что личность сформирована, выступает наличие у нее мировоззренческих начал, наряду с формированием которых происходит закладывание характера человека.

Характер личности, в свою очередь, связан с волей, которая определяется в качестве сознательной саморегуляции человеком своего поведения и поступков, качество которых определяется его способностью вести себя и действовать в соответствии с присущими ему принципами и нормами морали, что, безусловно, сопряжено с нравственностью. Свобода и ответственность личности, которая выражается во взаимодействии личных и общественных интересов, также связаны с ее нравственностью. Между интересами личности и интересами общества зачастую возникает противоречие (что хорошо и выгодно для личности в отдельности, не всегда полезно и приемлемо для общества). И это противоречие, которое не позволяет личности достигнуть желаемого и приводит к возможному конфликту с обществом, становится причиной противоправного, асоциального поведения, нередко приводящего личность на преступный путь.

Определить мотивы противоправного поведения, идущего вразрез с принятыми нормами правового поведения, на наш взгляд, не представляется возможным без исследования жизненного пути личности, решений и выборов, а также факторов влияния, которые индивид испытывал на себе и которые определяли формирование его личностных качеств в течение жизни.

При этом не следует опираться исключительно на однозначную зависимость между мотивами поведения и условиями жизни индивида, которые бы в обязательном порядке влияли на его противоправное поведение [1]. Можно лишь предположить, что неблагоприятные условия, в которых происходило формирование личности, имеют определяющее влияние на жизненный путь личности и ее правовое поведение, поскольку мотив поведения сосредоточивает в себе совокупность социальной среды и личностных качеств.

С точки зрения психологии личности, мотив имеет побудительную природу, другими словами, является причиной какого-либо действия, поступка, выражая тем самым личное отношение человека к объекту или субъекту, в адрес которого направлены его действия [6]. Таким образом, мотив дает возможность определить важные личностные черты, потребности и намерения человека, а также создает особенное личностное свойство, в котором сосредоточены наиболее важные жизненные ценности и представления личности. Следует уточнить, что мотив по своей природе не может быть противоправным, он не тождественен поведению, которое находится в зависимости от выбора средств реализации мотивов, уровней нравственности и правового сознания личности.

В психологической теории разработан ряд теорий о мотивации поведения, среди которых наиболее востребованными стали теория потребностей, теория справедливости и теория ожиданий (А. Маслоу, Д. Макгрегор, В. Врум). Так, согласно теории потребностей, последние выступают той движущей силой, которая отвечает за формирование и организацию в сознании личности процессов мышления, восприятия и действия, заставляя ситуацию неудовлетворенных потребностей развивать- 
ся в том направлении, которое бы обеспечило достижение желаемой цели, потребностей личности [7]. Потребности личности могут выражаться в деньгах, уважении, славе, безопасности и других ценностях. При этом страх, который человек испытывает от мысли, что он может лишиться своих потребностей, оказывает влияние на его способность учитывать общественные интересы - интересы и потребности других людей, соблюдать принятые в обществе нормы правового поведения.

Искажение нормы нравственного компонента правового поведения в совокупности с приобретенными личностными качествами отрицательной направленности (озлобленность, мстительность, корыстолюбие, обидчивость) приводят личность к действиям с отрицательной направленностью правового поведения. Это дает нам основание полагать, что противоправными являются не потребности личности, а асоциальные методы достижения этих потребностей.

К противоправному поведению (правовому поведению с негативной направленностью) личность может стремиться и по причине отклонений в нравственном воспитании и развитии, так называемой нравственной деградации. Такие отклонения проявляются в отсутствии у человека элементарных представлений о морали: чувстве долга, чести, достоинстве. В своих поступках и поведении такой человек руководствуется только тем, что выгодно ему, окружающие используются им исключительно для достижения своих потребностей и интересов, а все, что препятствует этому, преодолевается любыми противоправными способами. Нравственная деградация, проявляющаяся в поведении личности, наделенной определенными полномочиями в сфере власти, особенно опасна для общества, поскольку имеет возможность влияния на судьбу и жизненный путь других людей.

На поведение человека, противоправное оно или правомерное, также влияет жизненная ситуация, в которой он оказывается. Так, в кризисной ситуации человек поставлен перед выбором. В такой непростой ситуации он вынужден выбирать одну из возможных альтернатив, предпочтение которой обусловлено многими факторами, в числе которых эмоции, известные как динамическая сторона мотива поведения.

Одной из важных эмоций в контексте правового поведения личности возможно определить агрессию. При этом следует отметить, что агрессия не тождественна агрессивности. Например, А.А. Реан под агрессией понимает умышленные действия негативной эмоциональной направленности, результатом которых становится причинение вреда другому человеку или окружающим, под агрессивностью - качество личности, которое дает понять, что личность является потенциальным носите- лем агрессии и готова ее проявить при определенных обстоятельствах [4].

Смысловое различие понятий «агрессия» и «агрессивность» позволяет нам осознать, что различные агрессивные поступки в поведении личности являются следствием ее агрессивности. При этом агрессивность личности не всегда выливается в проявление агрессивного поведения с ее стороны. Проявление либо непроявление в поведении агрессивности как качества личности обусловлено результатом сложного взаимодействия всех факторов, относящихся к каждой конкретной ситуации. Так, если для личности не характерно качество агрессивности, но она в своем поведении демонстрирует агрессию, в качестве основной причины такого поведения с ее стороны возможно обозначить фактор ситуации. Если же личность по своей природе агрессивна, и в ее поведении отмечается агрессия, а также имеет место ситуативный фактор, то причина такого поведения, скорее всего, в личностном качестве - агрессивности.

Рассматривая агрессивность как фактор влияния на правовое поведение личности, важно определить личностные характеристики, порождающие агрессивное поведение. Среди них: раздражительность, страх общественного осуждения, подозрительность, способность испытывать чувство стыда.

Говоря об агрессии, она не появляется обособленно, в социальном вакууме, а порождается различным аспектами межличностного взаимодействия, посредством которых определяется направленность агрессии. Ключевыми детерминантами агрессии определены: фрустрация, негативное психическое состояние, возникающее при невозможности удовлетворения потребностей, когда желания личности не совпадают с ее возможностями; провокация, призыв к действиям негативной направленности. Физическая провокация зачастую влечет к тому, что люди проявляют агрессию, отвечая на агрессию со стороны другого лица или окружающих [7]. Происходит это, главным образом, для предотвращения возможности повторного проявления агрессии со стороны «нападающего», чтобы не выглядеть в глазах окружающих проигравшим, беспомощным.

Теоретический анализ источников, в которых исследуется феномен «правовое поведение» в рамках психологии личности, позволил нам детально осмыслить данное понятие. Мы рассматривали правовое поведение личности в двух противоположных плоскостях - правомерном и противоправном, данное разделение, на наш взгляд, чаще встречается в юридической психологии. В интересах настоящей статьи было заявлено о попытке подхода к понятию «правовое поведение» через психологию личности, в связи с чем противоположные 
плоскости правового поведения были определены как правовое поведение с положительной направленностью (социальное) и правовое поведение с негативной направленностью (асоциальное).

В процессе анализа были отмечены факторы влияния, которыми обусловлено то, будет ли правовое поведение с негативной направленностью либо с положительной. К основным факторам влияния мы отнесли условия жизни, уровень воспитания и нравственности, социальную среду, индивидуальный жизненный опыт, жизненную ситуацию. Следует отметить, что в каждой конкретной жизненной ситуации применительно к правовому поведению личности какие-то факторы будут более ярко выражены, а некоторые и вовсе могут не проявлять своего воздействия.

\section{ЛИТЕРАТУРА}

1. Данькова И.В. Роль социальных и психологических факторов в формировании асоциального поведения несовершеннолетнего в Республике Беларусь / И. В. Данькова / ЭЭлектронный ресурс] // Вестник КРу МВД России. 2019. - №2 (44). - Режим доступа: https://cyberleninka.ru/article/n/rol-sotsialnyh-ipsihologicheskih-faktorov-v-formirovanii-asotsialnogo-povedeniya-nesovershennoletnego-v-respublike-belarus

2. Зорина Е.А. Правовое поведение личности в современном российском обществе / Е.А. Зорина / [Электронный ресурс] // Новый взгляд. Международный научный вестник. - 2013. - №1. - Режим доступа: https://cyberleninka.ru/article/n/pravovoe-povedenie-lichnosti-v-sovremennom-rossiyskom-obschestve

3. Морозов А.С. Правомерное поведение как особый вид социального поведения человека / А.С. Морозов / [Электронный ресурс] // Вестник КемГУ. 2014. - №4 (60). - Режим доступа: https://cyberleninka.ru/article/n/pravomernoe-povedenie-kak-osobyy-vid-sotsialnogo-povedeniya-cheloveka

4. Реан А.А. Психология личности. Социализация, поведение, общение / А.А. Реан /. - М.: АСТ; СПб.: Прайм-Еврознак, 2007. - 198 с.

5. Сунцова Е.А., Чихладзе Л.Т., Яковлева 0.Н. 06 осмыслении особой формы правовой жизни индивида через правомерное поведение / Е.А. Сунцова, Л.Т. Чихладзе, 0.Н. Яковлева / [Электронный ресурс] // Вестник экономической безопасности. - 2019. - №3. - Режим доступа: https://cyberleninka.ru/ article/n/ob-osmyslenii-osoboy-formy-pravovoy-zhizni-individa-cherez-pravomernoe-povedenie

6. Тимошенко В.И. Социально-психологические факторы противоправного поведения / В.И. Тимошенко / [Электронный ресурс] // Вестник Пермского университета. - Юридические науки. - 2014. - №3(25). - Режим доступа: https://cyberleninka.ru/article/n/sotsialno-psihologicheskie-faktory-protivopravnogopovedeniya

7. Филимонова А.И., Авдеев Д.А. Привычки и их место в механизме правового поведения личности / А.И. Филимонова, Д.А. Авдеев / [Электронный ресурс] // Пробелы в российском законодательстве. - 2018. - №4. - Режим доступа: https://cyberleninka.ru/article/n/privychki-i-ih-mesto-v-mehanizmepravovogo-povedeniya-lichnosti

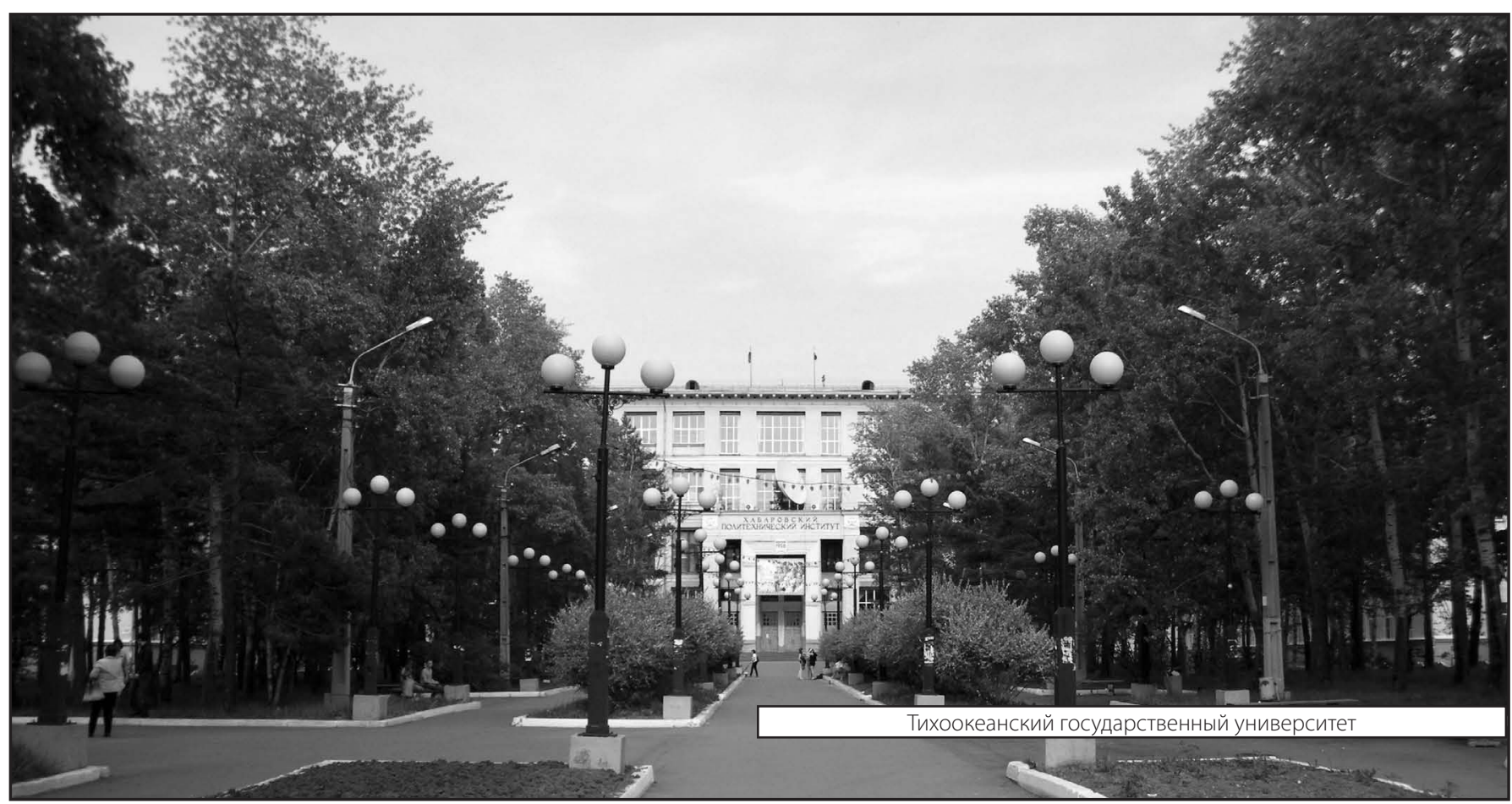

